\title{
PRE-TREATMENT OF INDUSTRIAL LANDFILL LEACHATE BY FENTON'S OXIDATION
}

\author{
D. PETRUZZELLI ${ }^{1 *}$ \\ G. BOGHETICH ${ }^{1}$ \\ M. PETRELLA ${ }^{1}$ \\ A. DELL'ERBA ${ }^{2}$ \\ P. L'ABBATE ${ }^{2}$ \\ S. SANARICA ${ }^{2}$ \\ M. MIRAGLIA ${ }^{3}$
}

Received: $14 / 11 / 05$

Accepted: 24/03/06

\author{
${ }^{1}$ Department of Civil and Environmental Engineering \\ The Polytechnic University of Bari \\ 4, Via Orabona, 70125 Bari, Italy \\ ${ }^{2}$ Department of Environmental Engineering and \\ Sustainable Development \\ The Polytechnic University of Bari \\ 8, Viale del Turismo \\ 74100 Taranto, Italy \\ ${ }^{3}$ Gruppo Ecolevante S.p.A. \\ S Croce sull'Arno $(P I)$, Italy
}

*to whom all correspondence should be addressed: e-mail: d.petruzzelli@poliba.it

\begin{abstract}
Biological treatment (aerobic and anaerobic) of industrial landfill leachate is limited by the presence of toxic contaminants (e.g., heavy metals) and recalcitrant (biopersistent) organics (e.g., polyphenols, pharmaceuticals, cosmetics, etc.,), hindering viable conditions for biomass proliferation in biological reactors, with difficulties in meeting concentration limits imposed by applied regulations.
\end{abstract}

Fenton's oxidation by the use of $\mathrm{Fe}^{2+}-\mathrm{H}_{2} \mathrm{O}_{2}-\mathrm{H}^{+}$mixture may be used as a pre-treatment of industrial landfill leachate for preliminary abatement of the organic load and to improve biodegradability $(\mathrm{BOD} / \mathrm{COD}>0.4)$ to favour biological oxidation in conventional wastewater treatment plants.

Leachate from Grottaglie (S.E. Italy) non-hazardous landfill $\left(\mathrm{pH} 8.6\right.$; COD $=11.000 \mathrm{mg} \mathrm{I}^{-1}$; $\mathrm{BOD}_{5}=2.400 \mathrm{mg} \mathrm{l}^{-1} ; \mathrm{NH}_{4}-\mathrm{N}=2.900 \mathrm{mg} \mathrm{I}^{-1}$; conductivity $=60.000 \mu \mathrm{S} \mathrm{cm}^{-1}$ ) was laboratory tested in different operative conditions, i.e., initial $\mathrm{pH}, \mathrm{Fe}^{2+} / \mathrm{H}_{2} \mathrm{O}_{2}$ ratio, concentrations and reaction time. The oxidation reaction was monitored by equilibrium $\mathrm{pH}$ and residual $\mathrm{COD}$ and $\mathrm{BOD}_{5}$ concentrations.

Best operative conditions were obtained at $\mathrm{pH} 3, \mathrm{Fe}^{2+}=700 \mathrm{mg} \mathrm{I}^{-1}, \mathrm{H}_{2} \mathrm{O}_{2}=9,900 \mathrm{mg} \mathrm{I}^{-1}$ $\left(\mathrm{H}_{2} \mathrm{O}_{2} / \mathrm{Fe}^{2+}\right.$ ratio $\left.13 \mathrm{w} / \mathrm{w}\right)$, reaction time $=2 \mathrm{~h}$. Following the oxidation reaction, solution $\mathrm{pH}$ was neutralized by the addition of $\mathrm{Ca}(\mathrm{OH})_{2}$ or $\mathrm{NaOH}\left(120\right.$ meq I$\left.^{-1}\right)$ for further abatement of target parameters by precipitation/sorption.

Preliminary technical/economical evaluation of possible process schemes is also given in the paper.

\section{KEYWORDS: advanced oxidation, industrial landfill leachate, Fenton's reagent}

\section{INTRODUCTION}

The main feature of current EU regulations on solid waste management (91/156 CE and EU $91 / 689 \mathrm{CE}$ ) is essentially based on "recovery, recycling and reuse" criteria. Nevertheless landfilling is still the most important technology for solid waste management. In the average, $60 \%$ of municipal solid wastes (MSW) produced, and even a larger fraction of industrial solid wastes (ISW), are still disposed-off in controlled landfilling [1].

Leachate formation, i.e., the liquid waste formed after weathering (rain, snowfalls) on the solid wastes, beyond the fraction released by intrinsic humidity and fermentation of solid wastes, is the main environmental impact during landfilling operation. The composition of such effluents 
is variable depending on type, origin and composition of the wastes, the structure, management and the "age" of the landfill $[2,3]$. Above considerations are strictly applicable to MSW leachate, the problem is amplified in reference to ISW leachate being the origin of the landfilled solids diversified depending on the productive activity of origin.

Treatment of such highly concentrated wastewater is based on physico-chemical methods, i.e., chemical co-precipitation of heavy metals coupled to sorption of bulk COD on cheap coagulants $\left(\mathrm{Ca}(\mathrm{OH})_{2}\right.$, polyelectrolytes) [4], or, in more advanced configurations, by the use of biosorbents such as lignocellulosic residues from the agri-food industry (olive-oil milling, winery, etc.). In this latter case biosorbents are used "once through" and the exhausted materials, containing massive quantities of contaminants, are disposed-off in the same landfill [5]. The use of more expensive sorbents such as activated carbon, adsorbent resins is possible with related economic implications. Alternatively, landfill leachate may be evaporated, incinerated or, in arid-semiarid areas, it may be re-circulated on the waste thus taking advantage of the evaporation favoured by the dry climatic conditions. Odour emissions is however the main limit of the operation [6].

Application of conventional biological treatment to reference liquors is limited by the presence of toxics (e.g., heavy metals) and/or recalcitrant organics (pharmaceuticals, polyphenols, endocrine disrupters) [7]. More than the generalised bio-toxicity, the technological problem is related to biorefractory nature of the organic matter due to the presence of high molecular weight substrates. Possibly, the autothrophic biomasses mediating hydrolysis of organic macromolecules are more sensitive to the mentioned toxicity and generalised non-viable conditions for biomass proliferation in the biological reactors.

Growing interest is lately focussed on the Advanced Oxidation Process (AOP) of landfills leachate with a multipurpose goal associated with: a) abatement of refractory COD load, with related enhancement of biodegradation after raising of the $\mathrm{BOD}_{5} / \mathrm{COD}$ ratio; b) simultaneous removal of toxic contaminants by sorption-coprecipitation [8].

AOP are based on the formation of hydroxyl radicals $(\mathrm{OH} \bullet)$, an extremely strong oxidant resulting from several reactions such as the synergistic action of two oxidants: $\mathrm{O}_{3}+\mathrm{H}_{2} \mathrm{O}_{2}$; a catalyst and an oxidant: $\mathrm{Fe}^{2+}+\mathrm{H}_{2} \mathrm{O}_{2}$ (the Fenton's reagent); a photocatalyst and an oxidant: $\mathrm{TiO}_{2}+\mathrm{H}_{2} \mathrm{O}_{2}$; irradiation plus oxidation: $\mathrm{UV}+\mathrm{O}_{3} / \mathrm{H}_{2} \mathrm{O}_{2}$ ); etc., $[9,10]$.

Generally speaking, full scale application of the Fenton's reagent does not requires supplementary operative costs beyond chemicals strictly needed for the oxidation reaction. In acidic media hydroxyl radicals are very efficiently formed for technical purposes. Chemicals are cheap, process layouts simple.

For proper design and control of full scale installations a basic knowledge of process principles and operative condition is needed. In the present paper, through laboratory experiments carried-out on the real leachate from Grottaglie (S.E. Italy) industrial landfill, is evaluated the influence of process operative parameters $\left(\mathrm{pH}\right.$, initial chemicals concentration and $\mathrm{Fe}^{2+} / \mathrm{H}_{2} \mathrm{O}_{2}$ ratio) on $\mathrm{BOD}_{5} / \mathrm{COD}$ ratio for enhancement of conventional biological treatment of the resulting liquids.

\section{GROTTAGLIE INDUSTRIAL LANDFILL}

Grottaglie landfill site is located in the Apulia Region (S.E.Italy), $4 \mathrm{~km}$ south of the town. It is classified as a former $2^{\text {nd }}$ Category type B installation, for "special-non-hazardous" industrial wastes according to the Italian legislation [11].

Fig. 1 shows a schematic view of the installation including two lots, with capacities exceeding $330,000 \mathrm{~m}^{3}$ (lot no.1) and 1,500,000 $\mathrm{m}^{3}$ (lot no.2) and surface 15,000 $\mathrm{m}^{2}$ (lot no.1), 28,000 (lot no.2, basin A) and $23,000 \mathrm{~m}^{2}$ (lot no.2, basin B). A $3^{\text {rd }}$ lot is underway and will be soon in operation. 


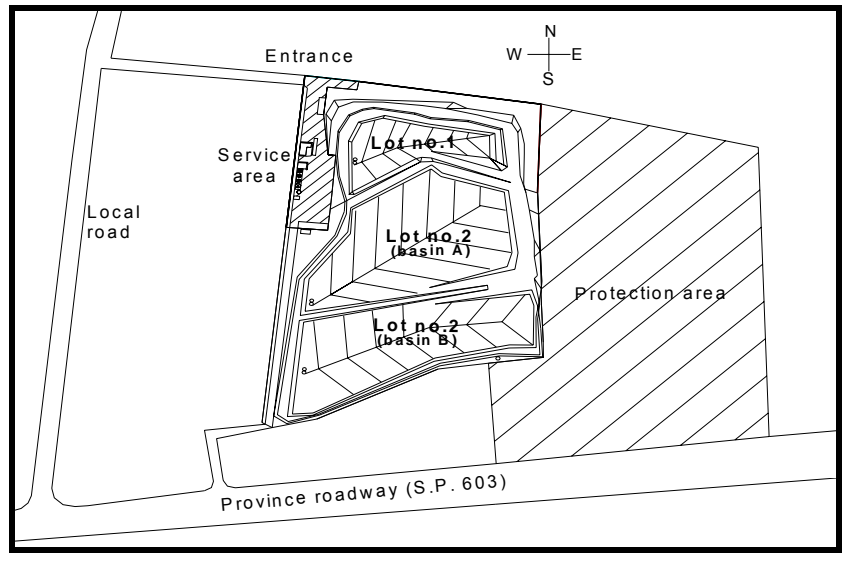

Figure.1. Layout of the Grottaglie industrial landfill

The annual leachate production (2003) for lot no. 1 exceeded $7,600 \mathrm{~m}^{3}$. The average composition is shown in Tab.1.

Table.1. Average composition of the leachate produced at Grottaglie landfill

\begin{tabular}{lclc}
\hline Parameter & Concentration $\left(\mathrm{mg} \mathrm{l}^{-1}\right)$ & Parameter & Concentration $\left(\mathrm{mg} \mathrm{l}^{-1}\right)$ \\
\hline COD & & & \\
$\mathrm{BOD}_{5}$ & 13,500 & $\mathrm{Al}$ & 0.5 \\
BTEX & 3,000 & $\mathrm{Cr}$ tot & 3 \\
Organic solvents & $<5$ & $\mathrm{Cr}(\mathrm{VI})$ & $<0.5$ \\
$\mathrm{~N}^{-N_{4}} \mathrm{H}_{4}$ & $<3$ & $\mathrm{Ni}$ & 0.5 \\
Oil-grease & 5,500 & $\mathrm{~Pb}$ & 0.5 \\
Dry residue $\left(105^{\circ}, 600^{\circ} \mathrm{C}\right)$ & 545,285 & $\mathrm{Hg}$ & $<0.5$ \\
Suspended solids & 700 & $\mathrm{Cu}$ & 0.5 \\
Chlorinated organics & $<5$ & $\mathrm{Sn}$ & $<0.5$ \\
pH & 8,5 & $\mathrm{Cd}$ & $<0.5$ \\
$\mathrm{BOD}_{5} / \mathrm{COD}$ & 0.22 & $\mathrm{Te}$ & $<0.5$ \\
Conductivity & $60,000 \mu \mathrm{S} \mathrm{cm}^{-1}$ & $\mathrm{Zn}$ & 5 \\
\hline
\end{tabular}

\section{EXPERIMENTAL}

Test leachate was characterised by the following relevant parameters: $\mathrm{pH} 8.7$; $\mathrm{COD}=10,915$ $\mathrm{mg} \mathrm{I}^{-1} ; \mathrm{BOD}_{5}=2,400 \mathrm{mg} \mathrm{I}^{-1} ; \mathrm{N}-\mathrm{NH}_{4}=2,880 \mathrm{mg} \mathrm{I}^{-1} ; \mathrm{Cr}(\mathrm{III})=9.8 \mathrm{mg} \mathrm{I}^{-1} ;$ Conductivity $=58,700$ $\mu \mathrm{S} / \mathrm{cm}$; and $\mathrm{BOD}_{5} / \mathrm{COD}$ ratio as low as 0.22 .

The leachate sampled at the landfill was preliminarily neutralised at $\mathrm{pH} 3.2$ by the addition of $\mathrm{H}_{2} \mathrm{SO}_{4}(98 \% \mathrm{w} / \mathrm{v})$. The amount of the added acid was pre-determined by separate titration.

To optimise operative $\mathrm{H}_{2} \mathrm{O}_{2} / \mathrm{Fe}^{2+}$ ratio, in a first set of experiments the acidic leachate $(\mathrm{pH} 3.2)$ was contacted with arbitrary amounts of $\mathrm{H}_{2} \mathrm{O}_{2}$ (i.e., 9,900 and 5,280 $\mathrm{mg} \mathrm{l}^{-1}$ respectively), from stock solution $(30 \% \mathrm{w} / \mathrm{v})$, followed by increasing amounts of $\mathrm{Fe}^{2+}$ from a stock solution $\left(\mathrm{FeSO}_{4} .7 \mathrm{H}_{2} \mathrm{O} 25 \% \mathrm{w} / \mathrm{v}\right)$. After $2 \mathrm{~h}$ contact time, stirring was stopped and the solution allowed to settle (1h). The supernatant solution was analysed for residual $C O D, B O D_{5}$ and $\mathrm{Cr}(\mathrm{III})$. Alternatively, at the end of the oxidation reaction and settling the mixture was added with $\mathrm{Ca}(\mathrm{OH})_{2}$ slurry or $5 \mathrm{M} \mathrm{NaOH}$ till neutralisation; a cation polyelectrolyte (Dryfloc 652 from Nymco Waters, Milan, Italy) was also added $\left(3 \mathrm{mg} \mathrm{I}^{-1}\right)$ to favour clarification and metals coprecipitation.

In a second set of experiments, constant the $\mathrm{H}_{2} \mathrm{O}_{2} / \mathrm{Fe}^{2+}$ ratio previously optimised, were carried-out tests at increasingly higher concentrations to verify the influence of potential limitations on the oxidation reaction operated by the chemicals addition to the liquid phase. In this case also, the oxidation reaction was completed by the neutralisation step using the mentioned alkalising agents and polyelectrolyte. 
A final experiment was carried-out in a gas tight system for collection and quali-quantitative characterisation of different outcoming products, i.e. gas, liquid, solid, resulting from the oxidation reaction.

\section{RESULTS AND DISCUSSION}

Fig. 2 shows $C O D$ abatement (residual fraction in the liquid-phase) after optimisation of the $\mathrm{H}_{2} \mathrm{O}_{2} / \mathrm{Fe}^{2+}$ ratio, for tests carried-out at 9,900 and $5,280 \mathrm{mgH}_{2} \mathrm{O}_{2} \mathrm{I}^{-1}$ respectively. In spite of different initial amounts of hydrogen peroxide dosed, the curves converge to steady values of residual COD after dosage of about 400 and $700 \mathrm{mgFe}^{2+} \mathrm{I}^{-1}$, corresponding to a constant ratio in the range $14 \mathrm{w} / \mathrm{w}$.

By assuming the following reactions presiding the Fenton's oxidation process:

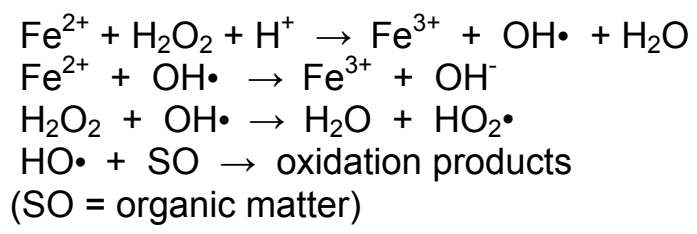

(radicals formation)

(side reaction)

(side reaction)

(oxidation reaction)

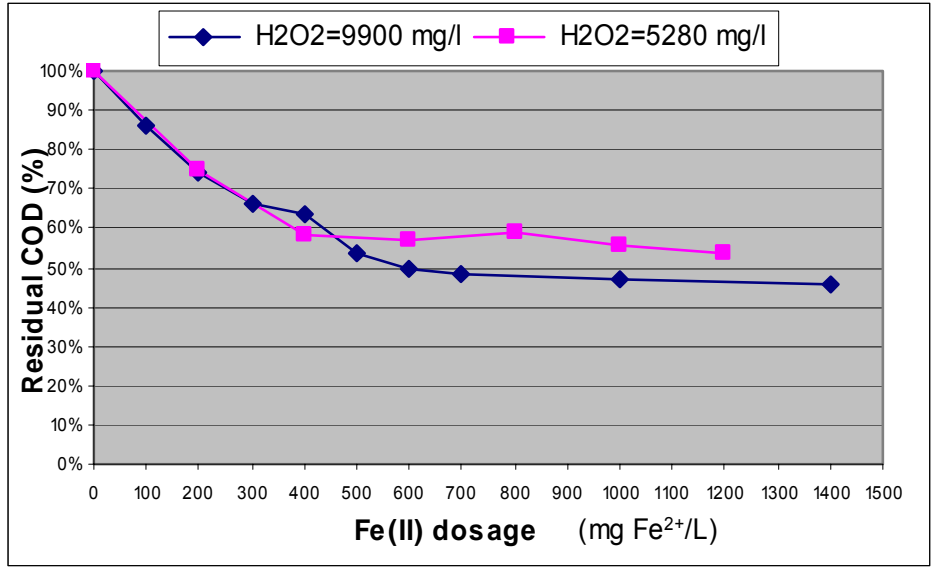

Figure 2. Fractional abatement of COD Vs. $\mathrm{Fe}^{2+}$ dosage for Grottaglie leachate

any excess dosage of chemicals should theoretically lead to a sensible reduction of free hydroxyl radicals (see side reactions above) thus inducing a minimum in the residual COD Vs. $\mathrm{Fe}^{2+}$ curve at the optimal ratio, followed by immediate raising due to depletion of $\mathrm{OH}$. with corresponding sensitive reduction of the COD abatement. This is actually not verified in Fig.2 and, accordingly, some other oxidation reaction mechanism(s) should be postulated for the reference Fenton's process, based on a more accurate chemical characterisation of the leachate.

Fenton's oxidation of the Grottaglie leachate leads to $\sim 50 \%$ abatement of the initial COD and $63 \%$ enhancement of the effluent biodegradability $\left(\mathrm{BOD}_{5} / \mathrm{COD}\right.$ ratio from 0.22 to 0.36) not too far from the indicated minimum figure (0.4) for efficient implementation of the aerobic biological treatment.

The addition of alkalising agents (lime slurry or caustic soda) and coagulation adjuvant (cationic polyelectrolyte) improves sensibly the quality of the oxidised liquid, in terms of reduced toxicity, after abatement of $40-70 \%$ trivalent chromium by using caustic or lime respectively, thus inducing sensible advantages to biological treatment to follow.

Based on the above results the following process scheme (Fig.3) may be proposed for potential upscaling of the Fenton's oxidation of the Grottaglie leachate. 


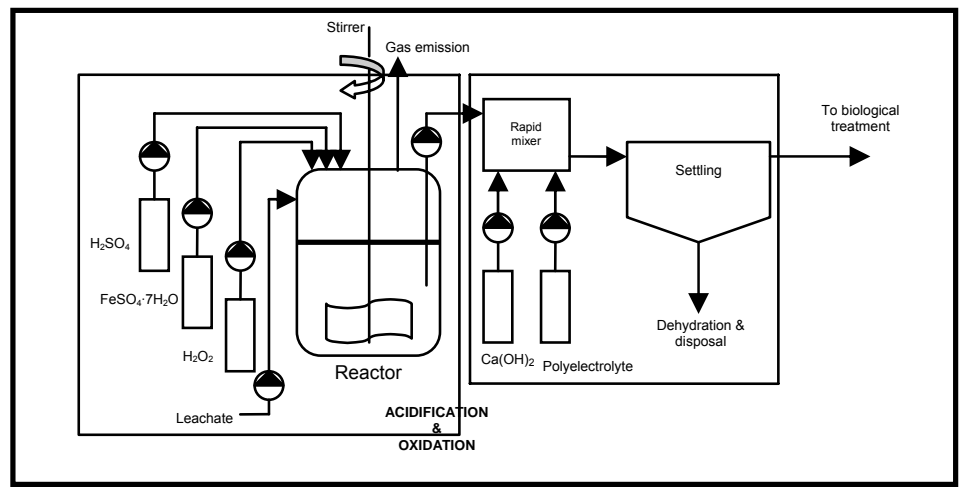

Figure 3. Schematic flow-sheet of the proposed Fenton's oxidation of Grottaglie leachate

Preliminary economic evaluation of the process indicates a tentative figure in the range of $9 € \mathrm{~m}^{-3}$ for the overall running costs of the process, including chemicals, power and maintenance. The figure appears definitely competitive as an "off-site" treatment of the landfill leachates based on conventional technologies, whose operative costs may exceed $20-30 € / \mathrm{m}^{3}$ depending on the final COD concentration.

\section{CONCLUSION}

A laboratory investigation was carried-out to verify potentialities of AOP (Fenton) pre-treatment of an industrial landfill leachate, with the aim of improving its biodegradability in view of conventional biological treatment to follow. To this aim the real leachate from Grottaglie landfill was tested under different operative conditions (i.e., initial $\mathrm{pH}, \mathrm{H}_{2} \mathrm{O}_{2} / \mathrm{Fe}^{2+}$ ratio, addition of coagulants, final neutralisation). Possible layouts for process upscale are now open for development at a larger scale which is underway.

As a consequence of the present work the following main conclusions may be drawn:

- COD abatement ranging $50 \%$ of the initial figure is obtained, by the adoption of a $\mathrm{H}_{2} \mathrm{O}_{2} / \mathrm{Fe}^{2+}$ ratio exceeding $14 \mathrm{w} / \mathrm{w}$;

- Enhancement of leachate biodegradation exceeding $60 \%\left(\mathrm{BOD}_{5} / \mathrm{COD}\right.$ from 0.22 to 0.36$)$ close to the threshold value set at 0.4

- Final clarification of the oxidised effluent by the use of cheap coagulants/precipitating agents [i.e., $\mathrm{Ca}(\mathrm{OH})_{2}, \mathrm{NaOH}$ ] and adjuvants (cationic polyelectrolytes) reduces final toxicity of the effluent after sensible reduction $(70 \%)$ of the residual $\mathrm{Cr}(\mathrm{III})$ concentration

- Based on a preliminary technical/economic evaluation, O\&M costs of the proposed process layout is in the range $9-10 € \mathrm{~m}^{-3}$, a figure highly competitive with conventional treatments costs (e.g., inertisation) in the same landfill.

\section{ACNOWLEDGEMENTS}

Technical cooperation of Ecolevante S.p.A. staff at the landfill site is gratefully acknowledged.

\section{REFERENCES}

1. Cameron E., Gardiner L. (2004) Catching-up fast. The waste challenge of a bigger Europe. Waste Managmt. World, May-June, 61-69.

2. Ehrig H.J. (1989) Leachate treatment overview, in T.H.Christensen et.al. eds. Sanitary landfilling - Process, Technology and Environmental Impact. Acad.Press London 285-297

3. Eckenfelder W.W. (2000) Industrial Water Pollution Control, $3^{\text {rd }}$ Ed. Mc-Graw-Hill, London, UK.

4. Haapea P., Kohrohnen S., Tukhanen T. (2002) Treatment of industrial landfill leachate by chemical and biological methods: Ozonation, ozonation+hydrogen peroxide, hydrogen peroxide and post-treatment for ozonated water, Ozone Sci.Eng., 24, 369-3778.

5. Volpe A. Lopez A., Pagano M. (2003) Olive husk. An alternative sorbent for removing heavy metals from aqueous streams, Applied Biochem.\& Biotechnol., 110, 137-150.

6. Blight G.E. (1989) Generation of leachate from landfills in water deficient areas", Sardinia '89 Int.Symp., Porto Conte, Sardinia, Italy.

7. Birkett J.W., Lester J.N. (2003) Endocrine Disrupters in Wastewater and Sludge Treatment Process. Lewis Pub.Co., CRC Press, Boca Raton, FL, USA. 
8. Bertanza G., Collivignarelli C., Pedrazzani R., Collivignarelli M.C., Zanaboni S. (2003) L'ossidazione chimica nel trattamento di acque di scarico e rifiuti liquidi; Esperienze e prospettive di ricerca, Ingegneria Ambientale, 38, 9-60.

9. Kang S., Chang H. (2000) Effect of reaction conditions on the oxidation efficiency in the Fenton process, Wat. Res., 34, 2786-2790.

10. Kim S., Geissen S., Volgepohl A. (1997) Landfill leachate treatment of by a photoassisted Fenton reaction, Wat.Sci.Technol., 35, 239-248.

11. Italian Decree no.22 (1997) on Solid Waste Management. 